\title{
A Convenient Approach to 2-Arylindenes via Suzuki Coupling Reaction of 2-Indenylboronate with Aryl Bromides
}

\author{
Dong-won Lee and Jaesook Yun* \\ Deparment of Molecular Science \& Technolog: Ajou University, Sinon 442-749. Korea \\ Received September 19.2003
}

Key Words : Suzuki coupling, 2-Arylindene, 2-Indenylboronate

[ndeny] derivatives have been extensively employed in organometallic chemistry as ligands.' Group 4 metallocene catalysts containing such ligands have shown activities in olefin polymerization ${ }^{2}$ as well as in various organic reactions of small molecules. "Recently, unbridged bis(2-arylindenyl)zirconium dichlorides were reported to produce elastomeric polypropylene with a stereoblock microstructure when activated by MAO (methylaluminoxane). " Waymouth and coworkers investigated several zirconocene catalysts containing a different aryl substituent in the 2-position of the indenyl ligand for their polymerization behavior, and reported that the bis(2-arylindenyl) framework was important for the production of elastomeric polyproplylene.

Although the importance of 2-arylindenes as ligands for olefin polymerization catalysts is increasing, only a couple of synthetic methods to 2-arylindenes have been reported. ${ }^{1.51}$ These reported procedures, however, have a serious limitation, as strongly basic reagents are required. The reaction of an organolithium reagent or arylmagnesium bromide with 2indanone is troublesome due to the susceptibility of 2indanone to enolization." This method is particularly ineffective for most organolithium nucleophiles as well as sterically demanding nucleophiles. The reaction utilizing 1,2-di(magnesiomethyl)benzene dichloride ${ }^{7}$ and the corresponding methyl ester of the substituent moiety was reported. ${ }^{\text {sb }}$ In this method, the starting methyl esters. if not commercially available, needed to be prepared separately and use of the di-Grignard reagent limited the functional group compatibility of this procedure. Therefore, a more convenient and general way to make a variety of 2-arylindenes is necessary.

We now report a synthetic route to a family of 2-arylindenes via Suzuki coupling reaction ${ }^{8}$ of 2-indenylboronate with various aryl bromides. To develop an efficient protocol, we initially focused on the preparation of an indenyl boron derivative as the coupling component. Since various aryl halides are commercially available, this approach seems more attractive than the coupling between bromoindene" and arylboronic acids. We found that Masuda's borylation procedure ${ }^{10}$ could be employed to prepare the indenylboron derivative. The original reaction conditions ${ }^{10 \mathrm{c}}$ was modified by changing the catalyst from $\mathrm{PdCl}_{2}(\mathrm{dppf}) / \mathrm{AsP}^{3} \mathrm{~h}_{3}$ to $\mathrm{PdCl}_{2}$ $\mathrm{PP}_{3}$ and applied to bromoindene. The desired indenylboronate 1 was obtained in $80-88 \%$ yield in either $1 \mathrm{HF}$ or dioxane at $80^{\circ} \mathrm{C}$ (Scheme 1). ${ }^{11}$ In this reaction, using an
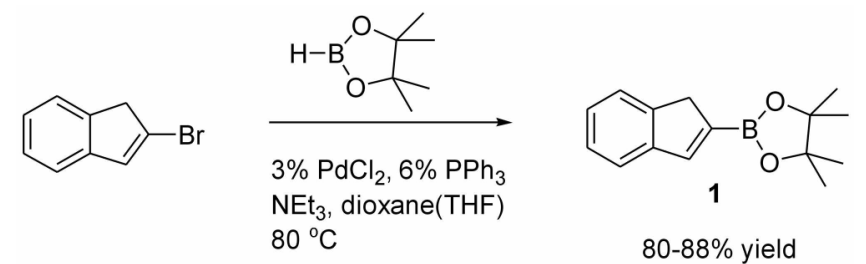

Scheme 1. Synthesis of 2-indenylboronate.

excess of toxic $\mathrm{AsPh}_{3}$ ligand with regard to the precatalyst was not necessary, and carrying out the coupling with a mixture of $\mathrm{PdCl}_{2}$ and $\mathrm{PPl}_{1}$; was enough to give the desired product in high yield.

Next, reaction conditions for the Suzuki coupling reaction of indenylboronate $I$ and bromobenzene were optimized ${ }^{12}$ by using $\mathrm{Pd}(\mathrm{OAc})_{2}$ as the precatalyst and $\mathrm{K}_{3} \mathrm{PO}_{4}$ as the base $^{1,3}$ (Table 1). THF or dioxane was more effective than toluene as a solvent, and $\mathrm{PPh}_{\hat{s}}$ was a better ligand than the other bidentate ligands that were screened. The coupling product, 2-phenylindene was isolated in $92 \%$ yield under the optimized conditions.

Other aryl halides were tested in the coupling reaction and the results are shown in Table $2{ }^{1 \cdot}$ Sterically hindered aryl halides with ortho substituents were effectively coupled to afford the corresponding 2-aryl substituted indenes in good yields (Jable 2, entries 2-4). Ortho substituents such as methyl, phenyl, and methoxy groups were accommodated. It

Table 1. Optimization of Suzuki coupling of 2-indenylboronate and bromobenzenc

\begin{tabular}{|c|c|c|c|}
\hline Entry & Ligand & Solvent & Yitzld $(\%)^{a t}$ \\
\hline 1 & $\mathrm{PPh}_{3}$ & THF & 92 \\
\hline 2 & $\mathrm{PPh}_{3}$ & diosane & 85 \\
\hline 3 & $\mathrm{PPh}_{3}$ & THF & $65^{s}$ \\
\hline 4 & $\mathrm{PPh}_{3}$ & toluene & 48 \\
\hline 5 & [PPB ${ }^{i}$ & THF & 71 \\
\hline 6 & DPPB & toluene & 50 \\
\hline 7 & $\mathrm{BINAP^{ \prime \prime }}$ & toluene & 55 \\
\hline
\end{tabular}

"Isolated yicld $>95 \%$ pure by ' $\mathrm{H}$ NMR. ${ }^{\circ} \mathrm{K}: \mathrm{PO}, \mathrm{H}_{2} \mathrm{O}$ was used instead of

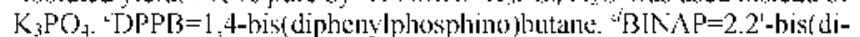
p-loly. Iphosphino)-1.1'-binaphthyl. 
Table 2. Suruki coupling of aryl bromides"

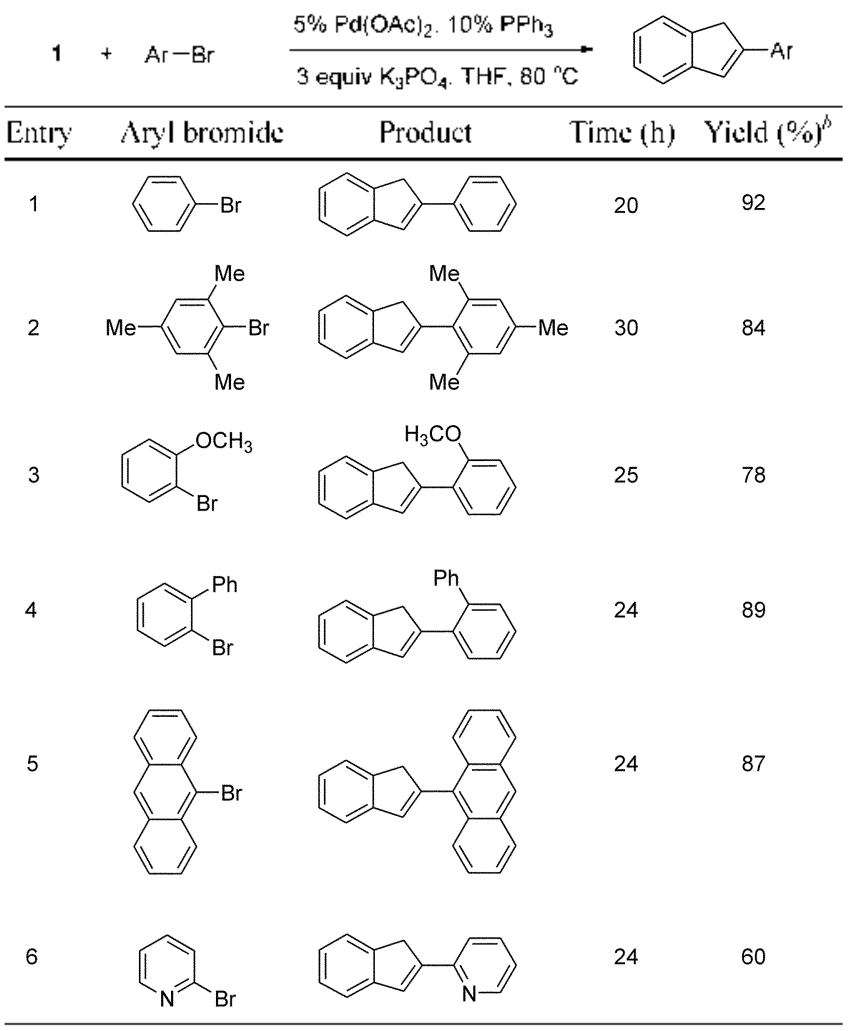

"Reaction conditions: I.0 equiv aryl bromide. I. I equiv 2-indenylboronate.

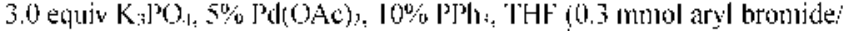
$1 \mathrm{ml}$. R reaction times have not been mimimized. "Isolated rields.

is notable that 9-bromoanthracene was reacted to form the corresponding product in good yield ( Table 2, entry 5, 87\%). The reaction conditions were also effective for the coupling of 2-bromopyridine ( Table 2, entry 6).

In sumınary, this method provides a versatile way to prepare a variety of 2-arylindenes in good to high yield. The mild reaction conditions which do not require the use of strong bases both in the preparation of 2-indenylboronate and in the Suzuki coupling reaction potentially allow a broad range of functional group variation in the coupled products. Work to extend the scope of this reaction is in progress.

Acknowledgement. The authors thank Ajou University for financial support of this work.

\section{References}

1. (a) Siemeling. U. (Chen. Rev. 2000. /00. 1495. (b) Kataoka. Y: Iwato, Y: Yamagati, T.: Tani, K. Ofgchometallics 1999. /8. 5423. (c) Cho. Y. 1.: Yoon. S. C.: Seo. W. S.: Woo. B3. W.: Bae. B.: Suh. I.: Park. J. T. Bull. Korean (hem. Soc. 1999. 20. 362 .

2. (a) Spalech. W.: Kueber. F.: Winter. A.: Rohemann. J.: Bachınann. B.: Antberg. M.: Dolle. V.: Paulus. E. F. Orgenometallics 1994. 13. 954. (b) Prosenc. M. H.: Janiak. C:: Brintzinger. H. H. Otgononetallics 1992. 11 . 4036. (c) I.eino. R.: Gomer. F. J.: Cole. A. P.: Waymouth. R. . . Hacromolectles 2001. 3H. 2072.

3. (a) Willoughby. C. A.: Buchwald. S. [. J. Am. Chem Soc. 1992. I/4. 7562 (b) Halterman. R. L.: Ramsey. I. M.: Chen. L.J. Org. Chen. 1994. 59. 2642. (c) Millward. D. B.: Colc. A. P.: Waymouth. R. M. Organometallics 2000. 19.1870.
4. Coates. G. W.: Waymouth. R. M. Science 1995. 267. 217.

5. (a) Ilauptman. F.: Waymouth. R. M.: 7iller. J. W. J. Am. Chent Soc. 1995, 117, I1586. (b) Witte, P.: [all, T. K.: Waymouth, R. V. Organonetalices 1999. 18.4147. (c) I.jn. S.: I Aauptman. F.: I al. T. K.: Waymouth. R. M.: Quan. R. W.: Ernest. A. B. J. Hol. C'atul. 1 1998. 136. 23. (d) Petoff' J. L. M.: Bruce. M. D.: Waymouth. R. M.: Masood. A.: Lal. T. K.: Quan. R. W.: Behrend. S. J Orgenometallics 1997. 16.5909.

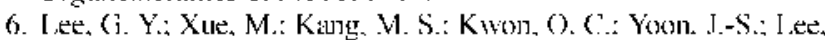
Y.-S.: Kim. II. S.: l.ee, HI. J.: [,e, l.-M, J. Organonet (Them. 1998. $55 x .11$

7. Lappert. M. F.: Martin. T. R.: Raston. C. L.: Skelton. B. W. Whitc. A. H. I. Chem. Soc., Dalon Trems. 1982. 1959.

8. For recent reviews. sce: (a) Miyaura N.: Suzuki. A. Chem. Rev. 1995. 95. 2457. (b) Suzuki. A.J. Organomet. (hem. 2002. 653. 83.

9. (a) Lindley. W. A.: MacDowell. D. W. H. I. Omg ( hem. 1982. 7 . 705. (b) Me Ewen. l.: Röntquist. M.: Ahlberg. I'. J. Am. Chem. Soc. 1993. $1 / 5.3989$.

10. For synthesis of arylboronates. se: (a) Murata M.: Watanabe. S.: Matsudia Y. J. Org. (hem 1997. 62.6458. (b) Muralit M.: Oyamin T.: Wattunabe. S.: Malsuda, Y. J. Org. Chem. 2000. 65. I64. For sonthesis of alkemylboronates from alkenyl trillates of iodides. sce: (c) Murata. M.: Oyana. T.: Watanabe. S.: Masuda. Y. Sinthesis 2000. 778 .

11. Synthesis of 2-Indenylboronate: $\mathrm{PdCl}_{2}(3,3 \mathrm{mg} .0 .19 \mathrm{mmol})$. $\mathrm{PPh}_{3}(98.6 \mathrm{meg} .0 .38 \mathrm{mmol})$ and bromoindene ( $\left.1.22 \mathrm{gg} .6 .27 \mathrm{mmol}\right)$ were placed in an oven-dried Sclolenk flask and dioxame $(25 \mathrm{ml})$ was added. liriethy lamine $(2.62 \mathrm{~mL} .18 .8 \mathrm{mmol})$ and 4.4.5.5tetranethyl-1.3.2-diosaborolane ( $1.36 \mathrm{~mL} .9 .40 \mathrm{mmol}$ ) were added suecessively by syringe at room temperature under nitrogen. The reaction tlask was stirred at $80^{\circ} \mathrm{C}$ for $5.5 \mathrm{~h}$. The reaction mixture was cooled $10 \mathrm{rom}$ temperature and quenched with water, and salturaled brine $(5 \mathrm{ml}$ ) was added. The organic layer was separated and the aqueous layer was exlracted with ellyl ether $(2 \times 20 \mathrm{~mL})$. The combincd organic lavers nere washed with brime. dried over $\mathrm{MgSO}_{4}$ and coneentrated. The residue was purified by Kugelrohr distillation to give 2-indenylboronate as at white solid (mp 73-74 ${ }^{\circ}$ () in $80 \%$ yield. The producl can be

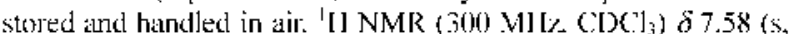
IH). $7.50(\mathrm{~d} . / 7 \mathrm{H}$. IH). $7.46(\mathrm{~d} . / 7 \mathrm{H} \angle . \mathrm{IH}) .7 .30-7.2 \mathrm{l}$ (m. 2H). 3.54 (s. $2 \mathrm{H}) .1 .33$ (s. $12 \mathrm{H}$ ): ${ }^{13} \mathrm{C}$ NMR $\left(75 \mathrm{MHz} . \mathrm{CDCl}_{3}\right) \delta$ 147.0. 145.7. 145.0. 126.3. 126.0. 124.0. 122.0.83.6. 41.7. 25.1.

12. For Suzuki coupling reactions of arylboronates with aryl halides. see: (a) Chaumeil. 11.: Signorellat. S.: Le IJian. C. Tetrahedron 2000. 56.9655. (b) \%hu. L.: Duquelte. J.: Thang. M. J. Org (hem. 2003. 68. 3729. (c) Satoh. Y.: Gude. C.: Chan. K.: Firooznia. F: Tetrohedron Lett. 1997. 38. 7645. For the Suzuki coupling of vinylboronates $w$ ith aromatic halides: (d) Eastwood. P. R. Tetrohedron lett $2000 .+1,3705$.

13. $\mathrm{A}$ better yield was obtained when anhydrous $\mathrm{K}_{3} \mathrm{PO} \mathrm{O}_{k}$, rather than $\mathrm{K}_{3} \mathrm{PO}_{4} \cdot \mathrm{H}_{2} \mathrm{O}$ was employed in our reactions. The use of $\mathrm{K}_{3} \mathrm{PO} \mathrm{O}_{4} \mathrm{~J} \mathrm{I}_{2} \mathrm{O}$ ) in alkyl-alkyl Suzuki coupling reaction. see: Netherton. M. R.: Dai. C.: Ncuschütz. K.: Fu. G. C. J. An. Chern. Soc. 2001. 123. 10099.

14. General procedure for Suzuki coupling of 2-indenylboronate and aryl bromides: An oven-dried restalable Schlenk tube was chaved with Pd(OAc) (3.4 mg. 0.015 mmol). PPh; $(7.9 \mathrm{mg}$. $0.030 \mathrm{mmol}$ ). 2-indenylboronate $(79.9 \mathrm{mg} .0 .33 \mathrm{mmol})$ and $\mathrm{K}_{3} \mathrm{PO}_{4}(19 \mathrm{lmg} .0 .90 \mathrm{mmol})$. The Schlenk tube was evacuated and backfilled with nitrogen. and THF ( $1 \mathrm{~mL})$ and the aryl bromido $(0.30 \mathrm{mmol})$ were added through a rubber septum (aryl bromides which were solids at room temperature were added prior to the evacuation/backlill cycle). The reaction Schlenk tube was sealed and was heated to $80^{\circ} \mathrm{C}$. lor the indicated amount of time. The reaction mixture was cooled to room temperature and liltered through a plug of $\mathrm{SiO}_{2}$. The filtrate was concentrated and the resulting residue was purified by flash chromatography to afford the desired product. 